\title{
Prevalence of the Metabolic Syndrome in Patients Presenting to the University Hospital of the West Indies: A Need to Adopt Proactive Screening and Specific Management Policy \\ M Gossell-Williams ${ }^{1}$, J Martin², S Neita², RC Gibson², W Abel², C Sewell², D McGrowder ${ }^{3}$
}

\begin{abstract}
Studies have shown that the metabolic syndrome (MetS), a major risk factor for the development of Type 2 diabetes mellitus and cardiovascular disease, is higher among psychiatric patients on antipsychotic medications than the general population. While studies on the prevalence of MetS in the Jamaican adult population have been undertaken, no such study has been done on the corresponding psychiatric population. The purpose of this study was to determine the prevalence of MetS in a Jamaican adult psychiatric inpatient population. The study group comprised thirty-eight patients with a primary DSM$I V$-TR Axis 1 diagnosis. Criteria for the diagnosis of MetS were the presence of any three or more of five factors as defined by using the International Diabetes Federation (IDF) and American Heart Association/National Heart Lung and Blood Institute (AHA/NHLBI) consensus agreement.

The prevalence of MetS in this cohort was $28.9 \%$ and was associated with significantly higher abdominal obesity $(p=0.010)$, elevated blood pressure $(\mathrm{p}=0.000)$, elevated triglycerides $(\mathrm{p}=0.019)$ and low high density lipoprotein-cholesterol $(\mathrm{p}=0.016)$ when compared with patients not diagnosed with MetS. Metabolic syndrome was common in this group of psychiatric patients and likely represents a pathway to the future development of Type 2 diabetes mellitus and cardiovascular disease. Screening and continuous monitoring will allow for early intervention and possibly prevention of increased morbidity and mortality in this vulnerable population.
\end{abstract}

Keywords: Abdominal obesity, antipsychotics, blood pressure, HDL-cholesterol, metabolic syndrome, triglycerides

\section{Prevalencia del Síndrome Metabólico en Pacientes que Acuden al Hospital Universitario de West Indies: Necesidad de Adoptar un Tamizaje Proactivo y Políticas de Tratamiento Específico}

M Gossell-Williams ${ }^{1}$, J Martin², S Neita², RC Gibson², W Abel², C Sewell², D McGrowder ${ }^{3}$

\begin{abstract}
RESUMEN
Los estudios han mostrado que el síndrome metabólico (SMet) - un factor de riesgo mayor para el desarrollo de la diabetes mellitus tipo 2 y la enfermedad cardiovascular - es más alto entre los pacientes psiquiátricos bajo medicamentos antipsicóticos que entre la población general. Si bien se han llevado a cabo estudios sobre la prevalencia del SMet en la población adulta jamaicana, no se han realizado estudios de esta clase en la población psiquiátrica correspondiente. El propósito de este estudio fue determinar la prevalencia del SMet en una población jamaicana adulta de pacientes hospitalizados. El grupo de estudio comprendió treinta y ocho pacientes con diagnóstico primario DSM-IV-TR de eje I. Los criterios para el diagnóstico de SMet se basaron en la presencia de tres o más de cinco factores, los cuales fueron definidos usando el acuerdo por consenso de la Federación Internacional de la Diabetes (FID) y la Asociación Nacional de Cardiología/Instituto Nacional del Corazón, el Pulmón y la Sangre (AHA/NHLBI).

La prevalencia de SMet en esta cohorte fue $28.9 \%$, y se hallaba asociada con obesidad abdominal significativamente más alta $(\mathrm{p}=0.010)$, presión sanguínea elevada $(\mathrm{p}=0.000)$, triglicéridos elevados
\end{abstract}

From: ${ }^{1}$ Department of Basic Medical Sciences, ${ }^{2}$ Department of Community Health and Psychiatry and ${ }^{3}$ Department of Pathology, The University of the West Indies, Kingston 7, Jamaica.
Correspondence: Dr M Gossell-Williams, Department of Basic Medical Sciences, The University of the West Indies, Kingston 7, Jamaica. E-mail: maxine.gossell@uwimona.edu.jm 
( $\mathrm{p}=0.019)$, y bajos niveles de colesterol-lipoproteína de alta densidad $(\mathrm{p}=0.016)$, al compararse con pacientes no diagnosticados con SMet. El síndrome metabólico fue común en este grupo de pacientes psiquiátricos y probablemente representa una vía al desarrollo futuro de la diabetes mellitus tipo 2 y la enfermedad cardiovascular. El tamizaje así como el monitoreo continuos permitirán la intervención temprana y la posible prevención del aumento de la morbosidad y la mortalidad en esta población vulnerable.

Palabras claves: Obesidad abdominal, antipsicóticos, presión sanguínea, colesterol HDL, síndrome metabólico, triglicéridos

West Indian Med J 2012; 61 (8): 803

\section{INTRODUCTION}

The Metabolic syndrome (MetS) has been defined as disturbances in metabolic factors, abdominal obesity, elevated fasting glucose, low high density lipoprotein (HDL)-cholesterol, elevated triglyceride and high blood pressure. The accepted classifications include that defined by the Adult Treatment Panel III (ATP III) of the National Cholesterol Education Programme (NCEP) and the modified ATP III proposed by the American Health Association. However, the most recent modification is defined using the International Diabetes Federation (IDF) and American Heart Association/ National Heart Lung and Blood Institute (AHA/NHLBI) criteria, which define MetS as abnormalities in three or more of these factors, taking ethnicity into consideration in defining abdominal obesity (1-3).

It is accepted that genetic factors and poor lifestyle practices of these patients, as well as many antipsychotics and other psychoactive drugs have been associated with increased risk of metabolic disturbances and development of MetS (4-7). In the United States of America and the United Kingdom, physicians are recommended to stringently monitor the metabolic status of psychiatric patients receiving antipsychotic drugs in recognition of the significantly higher risk of MetS development in these patients and the confounding cardiovascular complications that can be manifested $(6,7)$. While there is published data of the prevalence of MetS in the Jamaican adult $(8,9)$, there is no documentation of MetS in psychiatric patients or any of the possible metabolic disturbances associated with MetS. This study aimed at identifying the prevalence of MetS among this group of patients and determining whether there was a need to revisit patient management policies.

\section{SUBJECT AND METHODS}

The study was approved by the University Hospital of the West Indies/University of the West Indies/Faculty of Medical Sciences Ethics Committee.

All patients admitted to the psychiatric ward of the University Hospital of the West Indies (UHWI) from September 2009 to March 2010 and September 2010 to March 2011 were eligible to be part of this study if they had been diagnosed with a primary DSM-IV-TR Axis 1 diagnosis, were on antipsychotics, antidepressants or mood stabilizers for more than three months, over seventeen years old and consented to participation. For logistical reasons, a convenience sample of 38 patients was selected. Participants were included based on their availability and their satisfaction of the inclusion criteria, as well as on the availability of research personnel. Information collected included age, gender, height and drug history (including medications and dosages). Abdominal circumference was taken at the midpoint between the iliac crest and the lower rib. Sitting blood pressure was also measured using a standard mercury sphygmomanometer. All anthropometric data were collected by the same research assistant. Patients were asked to fast overnight (12 hours) for blood sample collection. A venous blood sample was taken from each research subject by the physician assigned to the study in two $\mathrm{BD}^{\circledR}$ Vacutainer tubes, potassium oxalate/sodium fluoride and silicone coated. Each sample was sent to the Chemical Pathology Laboratory at the UHWI and centrifuged using a Thermo Scientific Cl40 centrifuge at $3500 \mathrm{rpm}$. Serum was removed from the silicone coated tubes and stored at $-20{ }^{\circ} \mathrm{C}$ for lipid assays. The plasma was removed from the sodium fluoride tubes and assayed for glucose.

Biochemical assays on the serum were performed with a multi-channel Abbott Spectrum autoanalyzer (Abbott Laboratories, Abbott Park, Chicago, IL, USA). All assays were done in the Chemical Pathology Laboratory at the UHWI with the assistance of a Senior Medical Technologist. Factors that were determined include: fasting plasma glucose, total cholesterol, triglycerides, HDL-cholesterol and low density lipoprotein-cholesterol (LDL-cholesterol). Glucose concentration was measured using the glucose oxidase colorimetric test. Glucose oxidase catalyses the oxidation of glucose to gluconic acid. The generation of hydrogen peroxide is indirectly measured by oxidation of $o$-dianisidine in the presence of peroxidase (10). Total cholesterol was determined by an enzymatic method. The cholesterol esters are hydrolysed to free cholesterol by cholesterol esterase. The free cholesterol is then oxidized by cholesterol oxidase to cholesten-3-one with the simultaneous production of hydrogen peroxide. The hydrogen peroxide produced couples with 4-aminoantipyrine and phenol, in the presence of peroxidase, to yield a chromogen with maximum absorbance at $505 \mathrm{~nm}$ (11). High density lipoprotein cholesterol was measured by an enzymatic method on the supernatant obtained after selective precipitation of apolipoprotein B-containing lipoproteins 
with phosphotungstic acid, in the presence of magnesium ions and centrifugation (12). Serum LDL-cholesterol was calculated according to computational procedures of Friedewald [LDL-cholesterol $=$ total cholesterol - HDL-cholesterol - triglycerides/2.2 (mmol/L)] (13). Triglycerides concentrations were determined by an analytical method based on the sequence of reaction described by Fossati and colleagues (14, 15). In this direct colorimetric procedure, serum triglycerides are hydrolysed by lipase, and the released glycerol is assayed in a reaction catalysed by glycerol kinase and 1-alpha-glycerol-phosphate oxidase in a system that generates hydrogen peroxide. The hydrogen peroxide is monitored in the presence of horseradish peroxidase with 3, 5-dichloro-2hydroxybenzenesulfonic acid/4-aminophenazone as the chromogenic system. The absorbance of this chromogen system is measured at $510 \mathrm{~nm}$. The methods adopted by the automated instrument for the determinations of the above factors are according to the manufacturer's instruction (Abbott Laboratories, Abbott Park, Chicago, IL, USA).

Assessment of the presence of the factors associated with MetS were determined using the IDF and AHA/NHLBI consensus agreement classification, where the patient must have three or more of the following abnormalities: abdominal obesity (waist (cm): $M \geq 94 \mathrm{~F} \geq 80$ ); fasting glucose $\geq 100$ $\mathrm{mg} / \mathrm{dL}$ or on specific treatment; HDL-cholesterol: male $<40$ $\mathrm{mg} / \mathrm{dL}$, female $<50 \mathrm{mg} / \mathrm{dL}$ or on specific treatment; triglyceride $\geq 150 \mathrm{mg} / \mathrm{dL}$ or on specific treatment; blood pressure: systolic $\geq 130 \mathrm{mmHg}$ and/or diastolic $\geq 85 \mathrm{mmHg}$ or on specific treatment; this classification takes ethnicity into consideration. Abnormal body mass index (BMI) was defined on the basis of the World Health Organization (WHO) criteria of less than 18.5 being underweight, 25-29.9 as overweight and greater than 30 as obese.

Data were evaluated using descriptive statistics for demographic data. Daily dosages of antipsychotic medications were converted to chlorpromazine equivalents using drug comparison charts developed by Jensen and Regier (16).
Continuous variables were expressed as means and standard deviations (Mean $\pm \mathrm{SD}$ ) and comparisons were performed using the Mann-Whitney test for independent samples or Fisher's exact test as appropriate. Multivariate analyses were performed using logistic regression. Frequency counts and percentages were evaluated as categorical variables. In all statistical tests used, differences were considered significant at $p<0.05$.

\section{RESULTS}

A total of 38 patients were recruited. Table 1 shows the demographic and clinical characteristics of these participants. There were more $(63.2 \%)$ males than females and the mean age of all participants was $28.21 \pm 8.82$ years. The mean BMI was $24.62 \pm 4.07$ with $29 \%$ of participants being overweight (BMI $>25), 13 \%$ being obese $(\mathrm{BMI}>30)$ and one participant being underweight $(\mathrm{BMI}<18.5)$.

For most of the clinical factors assessed, there were no differences across gender, except for fasting glucose ( $p=$ 0.043 ) with males having higher levels than females. It was also observed that the mean HDL-cholesterol was abnormally low for both genders (normal HDL-cholesterol $>40$ $\mathrm{mg} / \mathrm{dL}$ for males; > $50 \mathrm{mg} / \mathrm{dL}$ for females).

Most of the patients were positive for at least one MetS related factor, with only seven patients $(18.4 \%)$ having none of the factors present, eight patients $(21.1 \%)$ had one factor, 13 patients $(31.6 \%)$ had two factors, 10 patients $(26.3 \%)$ had three factors and one patient (2.6\%) had four factors. Using the IDF/AHA/NHLBI consensus classification, the prevalence of MetS in this study was $28.9 \%(\mathrm{n}=11 ; 95 \%$ CI 14.5 , 43.3 ) with no difference across gender (males $=8 / 24,33.3 \%$; female $=3 / 14,21.4 \%$ ).

The prevalence of each MetS factor is displayed in the Figure. The MetS factor with the greatest disturbance was HDL-cholesterol, followed by abdominal obesity and then elevated blood pressure. Fasting blood glucose was least disturbed with only $5.3 \%$ of the patients having impaired fasting glucose concentrations.

Table 1: Demographics and clinical characteristics of enrolled patients

\begin{tabular}{|c|c|c|c|c|}
\hline & Total Mean \pm SD & $\begin{array}{c}\text { Male } \\
(24)\end{array}$ & $\begin{array}{c}\text { Female } \\
\text { (14) }\end{array}$ & $\begin{array}{c}p \text {-value for } \\
\text { Mann-Whitney } \\
\text { test } \\
\text { male } v s \text { female }\end{array}$ \\
\hline Age (yrs) & $28.21 \pm 8.82$ & $27.29 \pm 8.71$ & $29.79 \pm 9.12$ & 0.295 \\
\hline BMI & $24.62 \pm 4.07$ & $24.98 \pm 3.47$ & $24.01 \pm 5.03$ & 0.397 \\
\hline Waist (cm) & $85.90 \pm 14.89$ & $85.66 \pm 16.58$ & $86.54 \pm 12.00$ & 0.762 \\
\hline Fasting glucose $(\mathrm{mg} / \mathrm{dL})$ & $77.40 \pm 13.37$ & $80.93 \pm 4.36$ & $71.36 \pm 9.09$ & $0.043 *$ \\
\hline Total cholesterol $(\mathrm{mg} / \mathrm{dL})$ & $163.22 \pm 40.73$ & $166.65 \pm 42.44$ & $157.35 \pm 38.41$ & 0.525 \\
\hline HDL cholesterol (mg/dL) & $39.91 \pm 10.47$ & $37.60 \pm 9.97$ & $43.87 \pm 10.47$ & 0.087 \\
\hline LDL cholesterol (mg/dL) & $103.31 \pm 33.72$ & $108.83 \pm 32.99$ & $93.85 \pm 34.04$ & 0.303 \\
\hline Trigylcerides (mg/dL) & $99.6713 \pm 73.38$ & $101.06 \pm 69.98$ & $97.29 \pm 81.55$ & 0.904 \\
\hline Systolic BP/mmHg & $117.10 \pm 11.69$ & $117.92 \pm 10.10$ & $115.71 \pm 14.32$ & 0.534 \\
\hline Diastolic $\mathrm{BP} / \mathrm{mmHg}$ & $77.1053 \pm 8.85$ & $78.13 \pm 7.92$ & $75.36 \pm 10.33$ & 0.174 \\
\hline
\end{tabular}

$* p<0.05$

BMI - body mass index; HDL/LDL - high density/low density lipoprotein; BP - blood pressure 


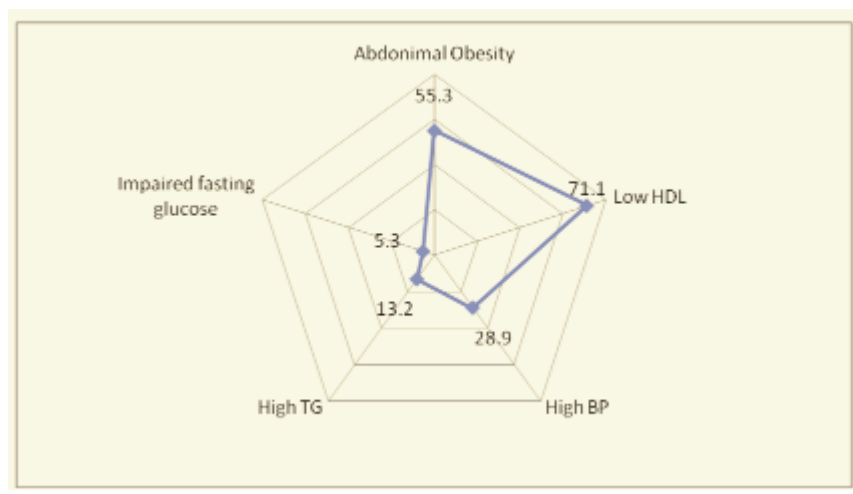

Figure: Prevalence of each of the metabolic syndrome (MetS) factor presented as percentage of the total number of patients in the study $(\mathrm{n}=38) ; \mathrm{HDL}$ - high density lipoprotein cholesterol; TG triglycerides; $\mathrm{BP}$ - blood pressure

Table 2 compares the presence or absence of the factors comprising MetS among persons meeting the criteria for MetS and those not meeting the criteria. Abdominal obesity was found in $91 \%$ and low HDL-cholesterol was found in all persons with MetS, as opposed to 41\% $(p=0.010)$ and $59 \%$ $(p=0.016)$, respectively of the participants who did not have MetS. For all other factors, prevalence rates were less than $100 \%$ among participants with MetS, but greater among this group than among persons who did not have MetS. These differences between both groups of patients were statistically significant for high blood pressure $(p=0.000)$ and elevated triglyceride levels (0.019), but not for elevated glucose.

Table 2: Prevalence of each of the metabolic syndrome (MetS) factors between patients assessed as having MetS and those not having MetS. Non-MetS may be displaying a maximum of two factors

\begin{tabular}{|c|c|c|c|c|}
\hline & & $\begin{array}{l}\text { IetS } \\
(\%)\end{array}$ & $\begin{array}{c}\text { No MetS } \\
\text { n (\%) }\end{array}$ & $\begin{array}{c}p \text {-value } \\
\text { derived from }\end{array}$ \\
\hline Abdominal obesity & Yes & $10(91)$ & $11(41)$ & $0.010^{*}$ \\
\hline & No & $1(9)$ & $16(59)$ & \\
\hline Elevated glucose & Yes & $1(9)$ & $1(4)$ & 0.501 \\
\hline & No & $10(91)$ & $26(96)$ & \\
\hline Low HDL-cholesterol & Yes & $11(100)$ & $16(59)$ & $0.016^{*}$ \\
\hline & No & $0(0)$ & $11(41)$ & \\
\hline Elevated TG & Yes & $4(36)$ & $1(4)$ & $0.019 *$ \\
\hline & No & $7(64)$ & $26(96)$ & \\
\hline Elevated BP & Yes & $8(73)$ & $3(11)$ & $0.000 *$ \\
\hline & No & $3(27)$ & $24(89)$ & \\
\hline Mean age $( \pm \mathrm{SD}) /$ year & & $31.5 \pm 12.2$ & $26.9 \pm 6.9$ & $0.383^{\mathrm{a}}$ \\
\hline Mean BMI $( \pm \mathrm{SD}) / \mathrm{kg} / \mathrm{m} 2$ & & $27.1 \pm 4.2$ & $23.6 \pm 3.6$ & $0.023^{\mathrm{a} *}$ \\
\hline
\end{tabular}

${ }^{a}$ Mann-Whitney test; ${ }^{a} p<0.05$

HDL - high density lipoprotein; TG - triglycerides; BP - blood pressure; BMI body mass index
Table 2 also compares age and BMI of patients with and without MetS. Body mass index was significantly higher $(p=0.023)$ among participants with MetS compared to participants without MetS. However, there were no differences in age observed between the groups.

Table 3 shows that most of the patients were taking more than one antipsychotic, antidepressants or mood stabi-

Table 3: Number of antipsychotics/antidepressants/mood stabilizers prescribed to patients

\begin{tabular}{lll}
\hline Number of drugs prescribed & Frequency & Patients with MetS \\
\hline 1.00 & $3(7.9 \%)$ & 0 \\
2.00 & $13(34.2 \%)$ & $3(27.3 \%)$ \\
3.00 & $15(42.1 \%)$ & $5(45.5 \%)$ \\
4.00 & $6(15.8 \%)$ & $3(27.3 \%)$ \\
\hline Total & $\mathbf{3 8}$ & $\mathbf{1 1}$ \\
\hline
\end{tabular}

lizers with most of the MetS patients taking three drugs. The predominant group of drugs was the typical antipsychotics, followed by the atypical antipsychotics, then the mood stabilizers and antidepressants (Table 4). Evaluation of anti-

Table 4: Drugs prescribed to all 38 patients in the group

\begin{tabular}{|c|c|}
\hline Drug & Frequency \\
\hline \multicolumn{2}{|l|}{ Typical antipsychotics (49) } \\
\hline Fluphenazine & 20 \\
\hline Haloperidol & 17 \\
\hline Chlorpromazine & 6 \\
\hline Trifluoperazine & 4 \\
\hline Zuclopenthixol & 2 \\
\hline \multicolumn{2}{|l|}{ Atypical antipsychotics (27) } \\
\hline Risperidone & 13 \\
\hline Quetiapine & 10 \\
\hline Olanzapine & 4 \\
\hline \multicolumn{2}{|l|}{ Antidepressants (2) } \\
\hline Escitalopram & 1 \\
\hline Fluoxetine & 1 \\
\hline \multicolumn{2}{|l|}{ Mood stabilizers (23) } \\
\hline Sodium valproate & 16 \\
\hline Lithium & 5 \\
\hline Carbamazepine & 1 \\
\hline Lamotrigine & 1 \\
\hline \multicolumn{2}{|l|}{$\begin{array}{l}\text { Other central nervous } \\
\text { system drugs (33) }\end{array}$} \\
\hline Benztropine & 28 \\
\hline Chlordiazepoxide & 2 \\
\hline Diazepam & 3 \\
\hline \multicolumn{2}{|l|}{ Non-psychotropic drugs (10) } \\
\hline Ranitidine & 2 \\
\hline Diphenhydramine & 2 \\
\hline Captopril & 2 \\
\hline Diclofenac & 2 \\
\hline Nicotine gum & 1 \\
\hline Bisacodyl & 1 \\
\hline
\end{tabular}


psychotics, antidepressants and mood stabilizers association with MetS is found in Table 5. Using Fisher's exact test, there was no single drug associated with the presence of MetS.

Table 5: Comparison of antipsychotics, antidepressants and mood stabilizers taken by patients with MetS versus no MetS

\begin{tabular}{lccc}
\hline Drugs & MetS & $\begin{array}{c}\text { No } \\
\text { MetS }\end{array}$ & $\begin{array}{c}\text { Fisher's } \\
\text { exact } \boldsymbol{p}\end{array}$ \\
\hline Carbamezipine & 0 & 1 & 1.00 \\
Chlordiazepoxide & 1 & 1 & 0.50 \\
Chlorpromazine & 3 & 3 & 0.32 \\
Diazepam & 1 & 2 & 1.00 \\
Fluphenazine & 7 & 13 & 0.48 \\
Fluoxetine & 0 & 1 & 1.00 \\
Haloperidol & 4 & 13 & 0.72 \\
Lamotrigine & 0 & 1 & 1.00 \\
LiCO3 & 3 & 2 & 0.13 \\
Olanzapine & 2 & 2 & 0.12 \\
Quetiapine & 5 & 5 & 0.11 \\
Risperidone & 3 & 8 & 1.00 \\
Sodium valproate & 6 & 10 & 0.47 \\
Trifluoperazine & 0 & 4 & 0.30 \\
Zuclopenthixol & 0 & 2 & 1.00 \\
& & & \\
\hline
\end{tabular}

Further analysis was done for patients taking antipyschotics. Chlorpromazine equivalents for patients' daily intake of typical and atypical antipsychotic medications are presented in Table 6. There was no significant deference between the dosages of patients with MetS and those without MetS irrespective of whether they were on typical or atypical antipsychotics.
Table 7: Logistic regression with presence or absence of metabolic syndrome as the outcome variable

\begin{tabular}{lccc}
\hline Co-variates & Odds ratio & $\mathbf{9 5 \%}$ CI & $\boldsymbol{p}$ \\
\hline $\begin{array}{l}\text { Atypical antipsychotics } \\
\text { (chlorpromazine equivalent) }\end{array}$ & 1.001 & $0.998-1.004$ & 0.646 \\
$\begin{array}{l}\text { Typical antipsychotics } \\
\text { (chlorpromazine equivalent) }\end{array}$ & 1.000 & $0.997-1.004$ & 0.820 \\
$\begin{array}{l}\text { Lithium dose } \\
\begin{array}{l}\text { Anti-epileptic drug } \\
\text { (present/absent) }\end{array}\end{array}$ & 1.000 & $0.997-1.003$ & 0.964 \\
$\begin{array}{l}\text { Benzodiazepine } \\
\text { (present/absent) }\end{array}$ & 0.837 & $0.058-11.981$ & 0.896 \\
Constant & 0.303 & & 0.668 \\
\hline
\end{tabular}

\section{DISCUSSION}

This is the first study to specifically look at the prevalence of MetS in patients with psychiatric disorders presenting to the psychiatric ward at the UHWI. While the majority of the patients were in the normal weight range, a large percentage was overweight or obese. The prevalence of MetS, as defined by the consensus between IDF and AHA/NHLBI guidelines among this group of psychiatric patients was $28.9 \%(\mathrm{n}=11 ; 95 \%$ CI $14.5,43.3)$. This rate is elevated when compared with the rates of $1.2 \%$ in a young adult population and $21.1 \%$ in a middle-aged adult population in Jamaica as reported by Ferguson et al during their 2010

Table 6: Mean chlorpromazine equivalents for patients' daily intake of typical and atypical antipsychotic medications

\begin{tabular}{lccc}
\hline & $\begin{array}{c}\text { MetS } \\
(\mathbf{n}=\mathbf{1 1})\end{array}$ & $\begin{array}{c}\text { No MetS } \\
(\mathbf{n}=\mathbf{2 7})\end{array}$ & $\begin{array}{c}\boldsymbol{p} \text {-value derived } \\
\text { from } \boldsymbol{t} \text {-test }\end{array}$ \\
\hline $\begin{array}{l}\text { Atypical antipsychotics: } \\
\text { chlorpromazine equivalents }\end{array}$ & $241.8 \pm 260.3$ & $203.4 \pm 266.6$ & 0.688 \\
$\begin{array}{l}\text { Typical antipsychotics } \\
\text { chlorpromazine equivalents }\end{array}$ & $275.2 \pm 289.9$ & $264.4 \pm 222.3$ & 0.900 \\
\hline
\end{tabular}

$* p<0.05$

In order to do further analysis to control for possible confounding effects of concurrent use of other medications with atypical antipsychotics, logistic regression was performed with the presence or absence of MetS as the outcome variable and chlorpromazine equivalents of typical and atypical antipsychotics, dosage of lithium and presence or absence of anti-epileptic drugs and benzodiazepines as covariates. Antidepressants were excluded from the model because they were used by only two patients. With the regression analysis, no relationship between chlorpromazine dose and the presence of MetS was detected (Table 7). population study using the same consensus criteria in a nonpsychiatric population (9). These findings are also elevated when compared to the rates found by Parekh et al in the United States of America general population as reported by the third National Health and Nutrition Examination Survey [NHANES III, 1988-1994] (17), which used the ATP III criteria. The elevation of the prevalence rate of MetS among the psychiatric population of this present study is also consistent with patterns found in the Danish study of a psychiatric population (18).

The patients in this study were relatively young, with the mean age being 28.2 years. For all of the factors ex- 
plored, the prevalence rates were higher among the participants with MetS compared to the participants without MetS, but the differences between the two groups were statistically significant for abdominal obesity, low HDL-cholesterol, elevated TG and high blood pressure but not for fasting glucose. Interestingly, abdominal obesity, low HDL-cholesterol and high blood pressure also had high prevalence rates among persons who did not fulfill the diagnostic criteria for MetS. If one views these as the factors that most distinguish patients with MetS from patients without MetS, then the patients without MetS are already at high risk.

The predominance of disturbances in these factors is consistent with other research findings done locally $(8,9)$ and in the NHANES study (17). Another similarity with the findings of Ferguson et al in younger adults (9) is that those authors also found low HDL-cholesterol to occur more frequently than abdominal obesity. Significantly, impaired fasting glucose was relatively uncommon in the majority of studies perused and was found to be the case in this study.

In this study, most of the patients were taking more than one psychiatric medication, ranging from typical or atypical antipsychotics, antidepressants and/or mood stabilizers with most of the patients diagnosed with MetS taking three medications. Previous research has demonstrated a welldocumented association between use of atypical antipsychotics and the development of obesity, dyslipidaemia and hyperglycaemia, as well as the progression into MetS $(6,19$, 20 ). More specifically, marked weight gain and elevations in triglyceride levels have been linked to olanzapine, quetiapine and risperidone use (3). Although no particular individual medications or class of medication were found to be associated with MetS, there are several other possible contributing factors which could explain why severe mood and psychotic disorders tend to be associated with higher rates of the MetS. Certain lifestyles which incorporate sedentary habits, diets rich in fats and carbohydrates are commonly found in persons suffering from a mental illness $(21,22)$. Severe mood and psychotic disorders may cause physiological changes that increase the rate with which MetS may develop. Insulin resistance and impaired glucose regulation have been documented in schizophrenic patients even before the development of the mental illness and before the introduction of psychiatric medication to the patient $(21,23)$. Studies also show that disregulation of the hypothalamopituitary-adrenal axis has been associated with the development of MetS $(24,25)$.

The generalizability of the study's findings is limited by the non-random method used for the selection of participants. In addition, the sampling method of the study made it impossible to make inferences about causal pathways. Limited medication history and small sample size also mitigated against detecting significant differences among subgroups. The results, however, support a need for larger studies to facilitate more definitive conclusions. In spite of these limitations, the findings of a high rate of MetS are consistent with other studies. It contributes to the mounting body of evidence which suggests that mentally ill patients are at increased risk for MetS. Of even more significance is the influence of these findings on patient management. The finding suggests that most psychiatric patients presenting for admission are likely to display at least one of the factors of MetS with low HDL-cholesterol concentrations being the most common anomaly, followed in decreasing order of importance by abdominal obesity and hypertension. Incorporating routine screening for these parameters in persons on psychotropic medications might be an important means of identifying persons in whom strategies to prevent MetS should be implemented. Caution should also be advised regarding the use of high doses of atypical antipsychotic medications.

\section{ACKNOWLEDGMENTS}

The authors of this paper would like to acknowledge the assistance given by the following undergraduate students: K Clarke, S Johnson, M Orr, as well as Mr K Grant, Senior Medical Technologist in the Chemical Pathology laboratory.

\section{REFERENCES}

1. Expert Panel on Detection, Evaluation, and Treatment of High Blood Cholesterol in Adults. Executive Summary of the Third Report of the National Cholesterol Education Program (NCEP) Expert Panel on Detection, Evaluation and Treatment of High Blood Cholesterol in Adults (Adult Treatment Panel III). JAMA 2001; 285: 2486-97.

2. Alberti KG, Zimmet P, Shaw J. The metabolic syndrome - a new worldwide definition. Lancet 2005; 366: 1059-62.

3. Alberti KG, Eckel RH, Grundy SM, Zimmet PZ, Cleeman JI, Donato $\mathrm{KA}$ et al. Harmonizing the metabolic syndrome: a joint interim statement of the International Diabetes Federation Task Force on Epidemiology and Prevention; National Heart, Lung, and Blood Institute; American Heart Association; World Heart Federation; International Atherosclerosis Society; and International Association for the Study of Obesity. Circulation 2009; 120: 1640-5.

4. Kabinoff GS, Toalson PA, Healey KM, McGuire HC, Hay DP. Metabolic issues with atypical antipsychotics in primary care: dispelling the myths. Prim Care Companion J Clin Psychiatry 2003; 5: 6-14.

5. Citrome L, Volavka J. Consensus development conference on antipsychotic drugs and obesity and diabetes: response to consensus statement. J Clin Psychiatry 2005; 66: 1073-4.

6. Barnett AH, Mackin P, Chaudhry I, Farooqi A, Gadsby R, Heald A et al. Minimising metabolic and cardiovascular risk in schizophrenia: diabetes, obesity and dyslipidaemia. J Psychopharmacol 2007; 21: 357-73.

7. Correll CU, Frederickson AM, Kane JM, Manu P. Does antipsychotic polypharmacy increase the risk for metabolic syndrome? Schizophr Res 2007; 89: 91-100.

8. Ferguson TS, Younger N, Tulloch-Reid MK, Forrester TE, Cooper RS, Van den Broeck $J$ et al. Prevalence of the metabolic syndrome in Jamaican adults and its relationship to income and education levels. West Indian Med J 2010; 59: 265-73.

9. Ferguson TS, Tulloch-Reid MK, Younger NO, Knight-Madden JM, Samms-Vaughan M, Ashley D et al. Prevalence of the metabolic syndrome and its components in relation to socioeconomic status among Jamaican young adults: a cross-sectional study. BMC Public Health 2010; 10: 307.

10. Huggett AS, Nixon DA. Use of glucose oxidase, peroxidase, and Odianisidine in determination of blood and urinary glucose. Lancet 1957; 273: $368-70$. 
11. Allain CC, Poon LS, Chan CS, Richmond W, Fu PC. Enzymatic determination of total serum cholesterol. Clin Chem 1974; 20: 470-5.

12. Burstein M, Scholnick HR, Morfin R. Rapid method for isolation of lipoproteins from human serum by precipitation with polyanions. J Lipid Res 1970; 11: 583-95.

13. Friedewald WT, Levy RI, Fredrickson DS. Estimation of the concentration of low density lipoprotein cholesterol in plasma, without use of the preparative ultracentrifuge. Clin Chem 1972; 18: 499-502.

14. Fossati P, Prencipe L. Serum triglycerides determined colorimetrically with an enzyme that produces hydrogen peroxide. Clin Chem 1982; 28: 2077-80.

15. McGowan MW, Artiss JD, Strandbergh DR, Zak B. A peroxidasecoupled method for the colorimetric determination of serum triglycerides. Clin Chem 1983; 29: 538-42.

16. Jensen B, Regier LD. Rx files drug comparison charts. $7^{\text {th }}$ ed. Saskatoon, SK: Saskatoon Health Region; 2008.

17. Parekh N, Roberts CB, Vadiveloo M, Puvananayagam T, Albu JB, LuYao GL. Lifestyle, anthropometric, and obesity-related physiologic determinants of insulin-like growth factor-1 in the Third National Health and Nutrition Examination Survey (1988-1994). Ann Epidemiol 2010; 20: 182-93.
18. Krane-Gartiser K, Breum L, Glümrr C, Linneberg A, Madsen M, Køster A et al. Prevalence of the metabolic syndrome in Danish psychiatric outpatients treated with antipsychotics. Nord J Psychiatry 2011: 65: 345-52.

19. Haupt DW, Newcomer JW. Hyperglycaemia and antipsychotic medications. J Clin Psychiatry 2001; 62 (Suppl 27): 15-26.

20. Atmaca M, Kuloglu M, Tezcan E, Ustundag B. Serum leptin and triglyceride levels in patients on treatment with atypical antipsychotics. J Clin Psychiatry 2003; 64: 598-604.

21. Brown S, Birtwistle J, Roe L, Thompson C. The unhealthy lifestyle of people with schizophrenia. Psychol Med 1999; 29: 697-701.

22. Davidson S, Judd F, Jolley D, Hocking B, Thompson S, Hyland B. Cardiovascular risk factors for people with mental illness. Aust N Z J Psychiatry 2001; 35: 196-202.

23. Meduna LJ, Gerty FJ, Urse VG. Biochemical disturbances in mental disorders. Arch Neurol Psychiatry 1942; 47: 38-52.

24. Siever LJ, Davis KL. Overview: toward a dysregulation hypothesis of depression. Am J Psychiatry 1985; 142: 1017-1103.

25. Brunner EJ, Hemingway H, Walker BR, Page M, Clarke P, Juneja M et al. Adrenocortical, autonomic, and inflammatory causes of the metabolic syndrome. Circulation 2002; 106: 2659-65. 